ARTICLE OPEN

\title{
Endosymbionts moderate constrained sex allocation in a haplodiploid thrips species in a temperature-sensitive way
}

\author{
Alihan Katlav ${ }^{1,3}$, Duong T. Nguyen ${ }^{1,2,3}$, Jennifer L. Morrow ${ }^{1}$, Robert N. Spooner-Hart ${ }^{1}$ and Markus Riegler (DD ${ }^{1 凶}$ \\ (c) The Author(s) 2022
}

Maternally inherited bacterial endosymbionts that affect host fitness are common in nature. Some endosymbionts colonise host populations by reproductive manipulations (such as cytoplasmic incompatibility; $\mathrm{Cl}$ ) that increase the reproductive fitness of infected over uninfected females. Theory predicts that $\mathrm{Cl}$-inducing endosymbionts in haplodiploid hosts may also influence sex allocation, including in compatible crosses, however, empirical evidence for this is scarce. We examined the role of two common Clinducing endosymbionts, Cardinium and Wolbachia, in the sex allocation of Pezothrips kellyanus, a haplodiploid thrips species with a split sex ratio. In this species, irrespective of infection status, some mated females are constrained to produce extremely malebiased broods, whereas other females produce extremely female-biased broods. We analysed brood sex ratio of females mated with males of the same infection status at two temperatures. We found that at $20^{\circ} \mathrm{C}$ the frequency of constrained sex allocation in coinfected pairs was reduced by $27 \%$ when compared to uninfected pairs. However, at $25^{\circ} \mathrm{C}$ the constrained sex allocation frequency increased and became similar between coinfected and uninfected pairs, resulting in more male-biased population sex ratios at the higher temperature. This temperature-dependent pattern occurred without changes in endosymbiont densities and compatibility. Our findings indicate that endosymbionts affect sex ratios of haplodiploid hosts beyond the commonly recognised reproductive manipulations by causing female-biased sex allocation in a temperature-dependent fashion. This may contribute to a higher transmission efficiency of $\mathrm{Cl}$-inducing endosymbionts and is consistent with previous models that predict that $\mathrm{Cl}$ by itself is less efficient in driving endosymbiont invasions in haplodiploid hosts.

Heredity (2022) 128:169-177; https://doi.org/10.1038/s41437-022-00505-5

\section{INTRODUCTION}

Inherited bacterial endosymbionts are common in nature and play pivotal roles in their hosts' biology, ecology and evolution (Buchner 1965). Some endosymbionts are beneficial because they confer a fitness advantage on their hosts by provisioning essential nutrients or providing protection against pathogens or environmental extremes (Douglas 2015); others are more parasitic and manipulate host reproduction to facilitate their transmission in host populations (Stouthamer et al. 2002; Oliver et al. 2010; Douglas 2015). Wolbachia and Cardinium bacteria are ubiquitous endosymbionts of arthropods (Weinert et al. 2015) and are inherited via the egg cytoplasm, while they are removed from sperm cells during spermatogenesis and, therefore, their paternal inheritance is very rare (Bressac and Rousset 1993; Doremus et al. 2020). Their maternal transmission has resulted in the evolution of host reproductive manipulations that select for an increased proportion of infected females in host populations (Hurst and Frost 2015; Zug and Hammerstein 2015). Common mechanisms of host reproductive manipulations are the induction of cytoplasmic incompatibility $(\mathrm{Cl})$, thelytokous parthenogenesis, male killing and feminization (Stouthamer et al. 2002). Furthermore, Wolbachia and Cardinium sometimes coinfect individuals of host species, and in such situations, either one (White et al. 2009) or both (Nguyen et al. 2017) can independently cause host reproductive manipulations. While affecting reproductive systems of hosts, reproductive manipulators that manipulate sex ratios also intrinsically affect sex allocation (Werren and Beukeboom 1998; Vala et al. 2003), and manifestation of this can vary depending on the hosts' sex determination system (Kageyama et al. 2012).

The most common form of host reproductive manipulation, $\mathrm{Cl}$, in its simplest form, occurs when eggs of an uninfected female are fertilized with sperm of an infected male (Werren et al. 2008). In diplodiploid species, $\mathrm{Cl}$ leads to embryonic mortality irrespective of the embryo's sex (Werren et al. 2008). However, this is not the case for haplodiploid species in which females can adjust production of diploid daughters and haploid sons via fertilisation control. In haplodiploids, $\mathrm{Cl}$ can lead to either the mortality of fertilized eggs (female mortality $\mathrm{FM}-\mathrm{Cl}$ ) or the conversion of individuals developing from fertilized eggs into males (male development $\mathrm{MD}-\mathrm{Cl}$ ); in contrast, unfertilised eggs remain unaffected and develop into males (Bordenstein et al. 2003; Vavre et al. 2003; Ros and Breeuwer 2009).

In general, $\mathrm{Cl}$ can confer a fitness advantage upon infected females as they are compatible with both infected and uninfected males, and, therefore, capable of offspring (including female) production, increasing the proportion of infected individuals

\footnotetext{
${ }^{1}$ Hawkesbury Institute for the Environment, Western Sydney University, Locked Bag 1797, Penrith, NSW 2751, Australia. ${ }^{2}$ New South Wales Department of Primary Industries, Elizabeth Macarthur Agricultural Institute, Private Bag 4008, Narellan, NSW 2567, Australia. ${ }^{3}$ These authors contributed equally: Alihan Katlav, Duong T. Nguyen

然mail: m.riegler@westernsydney.edu.au
} 


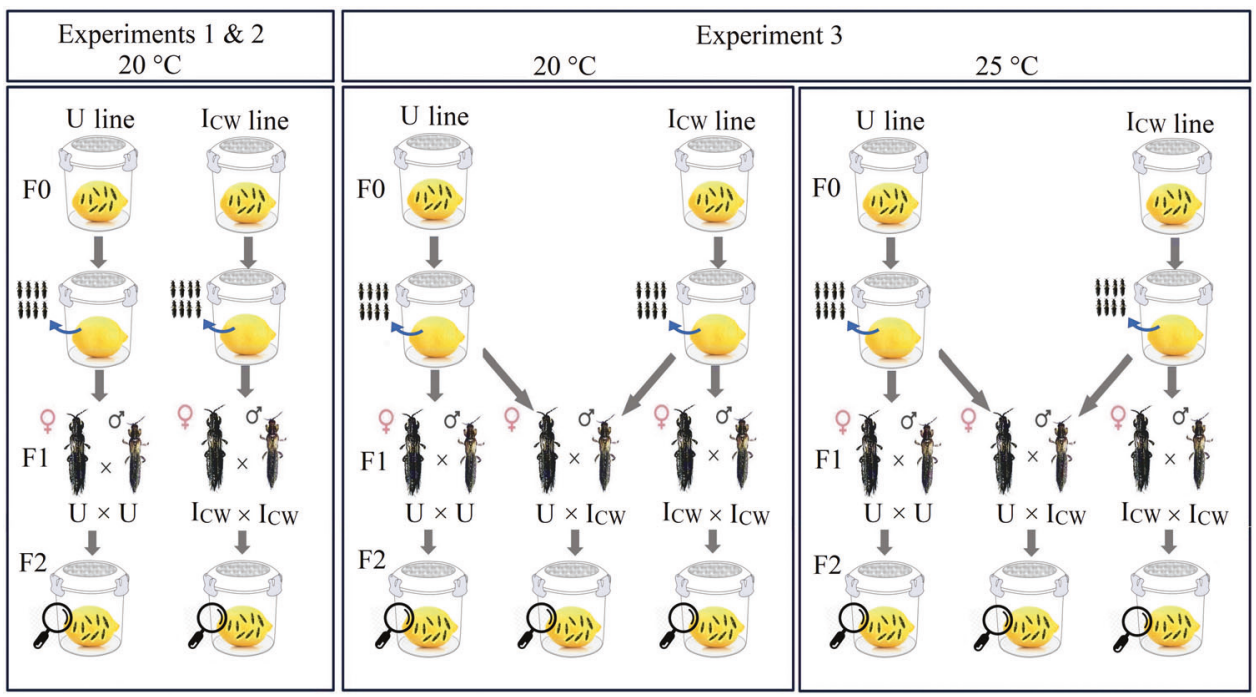

Fig. 1 Experimental design used to assess offspring number and sex ratio of compatible pairs of Pezothrips kellyanus infected with Cardinium and Wolbachia $\left(I_{\mathbf{c w}} \times I_{\mathbf{c w}}\right)$ or uninfected $(\mathbf{U} \times \mathbf{U})$. Experiment 3 also included the incompatible cross $\left(U \times I_{\mathrm{CW}}\right)$. Experiments $1-2$ were performed at $20^{\circ} \mathrm{C}$, while experiment 3 was performed at both 20 and $25^{\circ} \mathrm{C}$. Thrips were kept at temperature conditions for three generations (F0 to F2). F0 were kept at controlled density to produce the F1 pairs used in crossing experiments, and their offspring number and sex were assessed at the adult stage of F2. For better visualization, the thrips are depicted larger than their actual size.

which then increases the endosymbionts' prevalence and invasion success (Turelli 1994). However, a high frequency of uninfected individuals in host populations can hinder a $\mathrm{Cl}$-driven endosymbiont invasion. In particular, in haplodiploids the production of uninfected males in $\mathrm{FM}-\mathrm{Cl}$, and even more so in $\mathrm{MD}-\mathrm{Cl}$, may impede endosymbiont invasion. This is mainly because these uninfected males can subsequently mate with their uninfected mothers or other uninfected females which results in the production of uninfected females (Egas et al. 2002). Therefore, compared to diplodiploid hosts, haplodiploids require a higher proportion of infected individuals (i.e., a higher infection threshold level) before a $\mathrm{Cl}$-driven endosymbiont invasion can occur (Egas et al. 2002).

Theory suggests that in haplodiploid hosts, endosymbionts may require complementary strategies to increase the efficiency of $\mathrm{Cl}$. One strategy may be the manipulation of the host's sex allocation towards more female production, including by compatible infected pairs, and there is some evidence for this in the Wolbachia-infected spider mite Tetranychus urticae (Vala et al. 2003) and two Wolbachia-infected parasitoid wasp species (Vavre et al. 2000; Bordenstein and Werren 2000). Sex allocation influenced by other endosymbionts, Hamiltonella and Rickettsia, has also been documented in a whitefly species (Shan et al. 2019; Himler et al. 2011) and, for Wolbachia, even in a diplodiploid sheetweb spider (Gunnarsson et al. 2009). Nevertheless, the generality of this endosymbiont effect in other haplodiploid taxa and their underlying mechanisms remain unknown. Furthermore, how important abiotic factors such as temperature may affect endosymbiont-induced sex ratio biases is understudied, despite substantial evidence of the effects of temperature on endosymbiont densities and the expression of reproductive manipulations such as $\mathrm{Cl}$ and male killing, and, consequently, endosymbiont invasion dynamics (Hurst et al. 2000; Corbin et al. 2017; Doremus et al. 2019).

Thrips (Thysanoptera) have evolved haplodiploidy independently from Hymenoptera and other haplodiploid lineages such as wasps (Hymenoptera), scales and whiteflies (Hemiptera), and mites (Acariformes) (Evans et al. 2004; Nguyen et al. 2015). As with all haplodiploids, their maternal ability of sex ratio adjustment via fertilization control in response to biotic and abiotic conditions make thrips important model organisms for testing the generality of sex allocation theories in haplodiploids (Crespi 1992; 1993; Katlav et al. 2021a). In this study, we examined the effect of bacterial endosymbionts on the sex allocation in Pezothrips kellyanus (Thripidae), a native Australian haplodiploid thrips species which is naturally infected with one Cardinium strain and one Wolbachia supergroup B strain (Nguyen et al. 2016). This species reproduces by arrhenothoky, as only mated females can produce female offspring (Varikou et al. 2012; Nguyen et al. 2017). Based on comprehensive crossing experiments between infected and uninfected individuals, with analyses of egg hatch and survival to adulthood, it was found that both bacterial endosymbionts independently induce $\mathrm{Cl}$, with their coinfection resulting in $\mathrm{FM}-\mathrm{Cl}$; however, other reproductive manipulations such as male killing and feminization were excluded (Nguyen et al. 2017). Interestingly, females of $P$. kellyanus display condition-dependent constrained sex allocation which leads to split sex ratios among mated females, i.e., small mated females, despite successful insemination, produce extremely male-biased broods, whereas large mated females produce extremely female-biased broods (Katlav et al. 2021a), possibly to mitigate the costs of constrained sex allocation at the population level (Godfray 1990). However, it remains unknown whether the two maternally inherited endosymbionts can affect this split sex ratio pattern and/or whether the split sex ratio pattern is temperature-dependent. These questions are important as answers may apply to other haplodiploids more widely, including social hymenopterans in which split sex ratios are common and mainly associated with colony-based relatedness asymmetry (Keller et al. 2001).

Previous laboratory and field studies of $P$. kellyanus reported temperature-dependent and seasonally fluctuating sex ratio patterns at population levels (Varikou et al. 2012; NavarroCampos et al. 2013); yet it was unknown whether these patterns arose from endosymbiont infections and/or temperature effects on the sex ratio of individual broods. Here, we tested whether (1) individual females of a population naturally coinfected by Cardinium and Wolbachia are less likely to experience constrained sex allocation than uninfected individuals from which the endosymbionts had been removed by antibiotic treatment, (2) temperature moderates any such endosymbiont effects on constrained sex allocation, and (3) any such temperature effects on endosymbiont-influenced sex allocation correlate with 


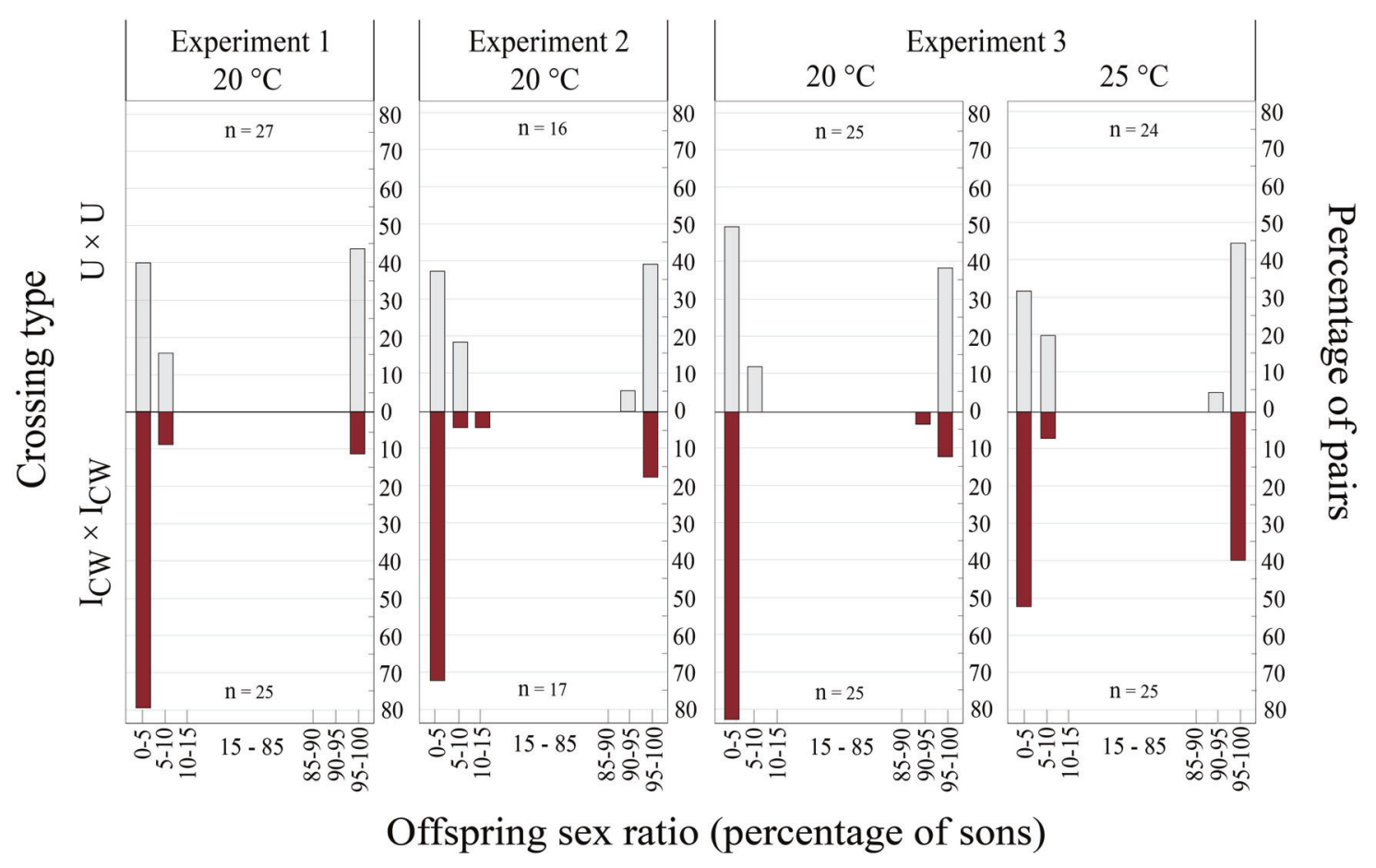

Fig. 2 Frequency distribution of uninfected $\left(U \times U\right.$; top) and endosymbiont-infected $\left(I_{\mathrm{CW}} \times I_{\mathrm{CW}}\right.$; bottom) pairs (\% of pairs) producing particular offspring sex ratios (\% of sons). The crossing experiments revealed bimodal sex ratio patterns, with some mated females producing male-biased (M) broods (constrained females) and other mated females producing female-biased (F) broods (unconstrained females). Experiments 1-2 evaluated the percentage of constrained and unconstrained mothers at $20^{\circ} \mathrm{C}$, and experiment 3 at 20 and $25^{\circ} \mathrm{C}$.

temperature-dependent changes in endosymbiont densities and/ or $\mathrm{Cl}$ strength. Addressing these questions will help further uncover the epidemiological dynamics of endosymbionts in haplodiploid host populations and reveal factors that drive the evolution of constrained sex allocation and split sex ratios.

\section{METHODS}

\section{Establishment and maintenance of laboratory lines}

A laboratory population of $P$. kellyanus originally established with individuals collected from the Riverland, South Australia, was used for this experiment. This population was naturally coinfected $\left(I_{C W}\right)$ with one Cardinium strain and one Wolbachia supergroup B strain (Supplementary Information; Nguyen et al. 2016). Thrips were reared as described by Nguyen et al. (2017). All the experiments were conducted in environmental chambers set at controlled conditions of $70 \% \pm 1.6$ relative humidity (mean \pm SE), $16: 8 \mathrm{~h}$ (light:dark) and $20^{\circ} \mathrm{C} \pm 0.04$ (experiments $1-3$ ) or $25^{\circ} \mathrm{C} \pm 0.05$ (experiment 3 ). To establish an uninfected line $(U)$, adults of the coinfected line $\left(I_{\mathrm{CW}}\right)$ were treated with a $5 \%$ rifampicin $(\mathrm{w} / \mathrm{v})$ solution for three generations (Nguyen et al. 2017) followed by recovery from antibiotic effects for at least two generations prior to the experiments. Individuals were tested for endosymbiont infection status as described by Nguyen et al. (2016).

\section{Experimental design}

Data were collected in three consecutive crossing experiments (Fig. 1) that assessed offspring number and sex ratios at the adult stage in crosses between compatible pairs of coinfected $\left(\mathrm{I}_{\mathrm{CW}} \times \mathrm{I}_{\mathrm{CW}}\right)$ and uninfected $(\mathrm{U} \times \mathrm{U})$ individuals; experiment 3 also included the $\mathrm{Cl}$ cross $\left(U \times I_{C W}\right)$. Singly infected lines were not available when the experiments were conducted. Therefore, experiments 1 and 2 addressed the combined effect of both endosymbionts on offspring number and sex ratios of females reared at $20^{\circ} \mathrm{C}$ only, whereas in experiment 3 , the offspring number and sex ratio effects of the coinfecting endosymbionts were assessed at 20 and $25^{\circ} \mathrm{C}$. At these temperatures different sex ratios have previously been reported for $P$. kellyanus at the population level (Varikou et al. 2012), and, generally, these temperatures are experienced by $P$. kellyanus in the field. The temperature treatments were implemented for at least two generations prior to the experimental data collection; i.e., F0 individuals were reared at the experimental temperatures from egg to adult, the F1 offspring were used to set up crossing experiments and their offspring (F2) number and sex ratio were measured at the adult stage. Cardinium and Wolbachia infections of each line were confirmed by PCR screening of randomly selected 20 females and 20 males per line before each experiment commenced.

For the crossing experiments, we used similar-aged individuals ( 1 day old virgin females and 1-2 days old virgin males) which had been reared at controlled densities. For this, F0 females and males of each line were placed into small round plastic containers (diameter $10 \mathrm{~cm}$; height $11.5 \mathrm{~cm}$; with filter paper on the bottom and a lid with a thrips mesh-covered opening), containing one fully ripe lemon fruit each, to oviposit for $24 \mathrm{~h}$ after which the adults were removed (Fig. 1). An ad libitum amount of Typha sp. pollen was added to increase female fecundity (Varikou et al. 2009). Upon pupation of their offspring, pupae of each line were separated by sex and transferred to individual Petri dishes (diameter $60 \mathrm{~mm}$; height $15 \mathrm{~mm}$ ) with a moist filter paper. One day after adult emergence ( $F 1)$, each virgin female was transferred to a Petri dish (diameter $35 \mathrm{~mm}$, height $10 \mathrm{~mm}$ ) together with ten virgin males (1-2 days old) and Typha sp. pollen. Once mating had started with one male, the copulation activity of individual pairs was monitored to ensure that mating was not disrupted. Then each individual pair was transferred onto one lemon fruit in a small round plastic container (Nguyen et al. 2017; Katlav et al. 2021a) and ad libitum Typha sp. pollen was added and replenished every second day. The pairs were removed after the mated females were allowed to lay eggs, first for 14 days in experiments 1 and 2, and then for a total of ten days in experiment 3 because we found that most females laid their eggs within the first ten days. Offspring were reared until adulthood (F2) for recording of the offspring number and sex ratio (Fig. 1).

\section{Effects of endosymbionts and temperature on offspring number and sex ratio}

Upon emergence of all adults, number and sex ratio of offspring (F2) produced by each individual mother was recorded. As in other similar studies, any pair that had produced fewer than ten offspring was excluded (Snook et al. 2000). In our study this applied to only one $U \times U$ pair in experiment 2 and 3 each. Offspring sex ratio of each individual female was calculated as the percentage of male offspring in the brood. Consistent 
with a previous study (Katlav et al. 2021a), females showed a bimodal sex ratio pattern and were thus grouped into two categories depending on the percentage of male offspring: constrained females with $85-100 \%$ male offspring ( $\mathrm{M}$ broods) and unconstrained females with $0-15 \%$ male offspring ( $\mathrm{F}$ broods). Due to the bimodal nature of sex allocation in this species, a mixed effects logistic regression was used to analyse the effect of "infection status" and "temperature" (as two binary fixed factors; infected vs. uninfected; 20 vs. $25^{\circ} \mathrm{C}$ ) on the probability of constrained sex allocation. We incorporated "total offspring number" as covariate and "experiment number" as random factor. The mixed effects logistic regression analyses for sex ratio data were performed using a generalized linear mixed effects model (glmer function) with ("family = binary"; $a=$ 0.05) in the "Ime4" package in R version 3.5.1 (R Development Core Team 2015). We further assessed the role of endosymbiont and temperature on sex ratio for constrained and unconstrained females separately. According to a Shapiro-Wilk test the sex ratio data had a non-normal distribution; therefore, we used a Wilcoxon rank sum test in $\mathrm{R}$ to compare group means.

\section{Effect of temperature on $\mathbf{C l}$}

Previous experiments conducted at $20^{\circ} \mathrm{C}$ demonstrated that Cardinium and Wolbachia coinfection caused complete $\mathrm{Cl}$ of the $\mathrm{FM}-\mathrm{Cl}$ type in $\mathrm{U} \times \mathrm{I}_{\mathrm{CW}}$ crosses of $P$. kellyanus (Nguyen et al. 2017). Besides compatible pairs $\left(I_{\mathrm{cw}} \times\right.$ $\left.\mathrm{I}_{\mathrm{CW}} ; \mathrm{U} \times \mathrm{U}\right)$, experiment 3 also included incompatible pairs $\left(\mathrm{U} \times \mathrm{I}_{\mathrm{CW}}\right)$ at both 20 and $25^{\circ} \mathrm{C}$. This enabled us to assess whether the strength and type of $\mathrm{Cl}$ changed with temperature. This was achieved by comparing the number of male vs. female offspring across the two temperatures. According to a Shapiro-Wilk test the normality assumption was not met for the $\mathrm{Cl}$ data. Therefore, the $\mathrm{Cl}$ dataset was processed using Aligned Rank Transform in the ARTool package (Wobbrock et al. 2011) in R to then perform a nonparametric ANOVA, as previously conducted for other Cl studies (Nguyen et al. 2017), followed by pairwise comparisons with Tukey post hoc tests.

\section{Quantification of endosymbiont density}

In another experiment endosymbiont densities were measured after rearing thrips for two consecutive generations (G1-G2) across four different temperature regimes: (1) both generations at $20^{\circ} \mathrm{C}(20-20) ;(2)$ both generations at $25^{\circ} \mathrm{C}(25-25) ;(3) \mathrm{G} 1$ at $25^{\circ} \mathrm{C}$ and $\mathrm{G} 2$ at $20^{\circ} \mathrm{C}(25-20) ;(4) \mathrm{G} 1$ at $25^{\circ} \mathrm{C}$ and $\mathrm{G} 2$ at $30{ }^{\circ} \mathrm{C}(25-30)$ (see Supplementary Information; Table S1). From each treatment three to five newly emerged $G 2$ adult females and males were sampled, except for the 25-30 treatment for which most G1 adult mothers died due to unknown reasons, and offspring (G2) were obtained from only three females of unknown mating status, and they only produced males. The $\mathrm{G} 2$ individuals from all treatments were subjected to DNA extraction and quantitative PCR with gyrB as a Cardinium gene, coxA and $f b p A$ as two Wolbachia genes, and Efla as a host reference gene (for details about DNA extraction and quantitative PCR see Supplementary Information; Tables S2-S3; Nguyen et al. 2017). Relative symbiont densities were calculated following normalisation to the host gene using $2^{-\Delta \mathrm{Cq}}$ (Schmittgen and Livak 2008). The effects of "thermal regime" and "sex" on endosymbiont densities were analysed as fixed factors using a general linear mixed effect model (Imer function) with the "Ime4" and "car" packages in $\mathrm{R}$.

\section{RESULTS}

Effects of endosymbionts and temperature on constrained sex allocation

Mated $P$. kellyanus females displayed a bimodal sex ratio pattern, i.e., some mated females were not constrained and had $\mathrm{F}$ broods (0-15\% males), whereas other mated females were constrained and had $\mathrm{M}$ broods (85-100\% males) (Fig. 2). At $20^{\circ} \mathrm{C}$ across all experiments, about $85 \%$ of 67 mated females with both endosymbionts $\left(\mathrm{I}_{\mathrm{CW}}\right)$ produced $\mathrm{F}$ broods with an average sex ratio of $1.7 \%$ males, while $<58 \%$ of 66 mated females without endosymbionts $(U)$ produced $F$ broods with an average sex ratio of $4.5 \%$ males (Fig. 2). Therefore, mated $U$ females were more likely constrained to $M$ brood production $(42 \%$ constrained females) than $\mathrm{I}_{\mathrm{CW}}$ females $\left(15 \%\right.$ constrained females) $\left(\mathrm{F}_{1,183}=\right.$ 9.89; $P<0.001)$. Moreover, in experiment 3 the proportion of females producing $\mathrm{M}$ broods was higher at $25^{\circ} \mathrm{C}$ (38\% of the 50 mated females) than at $20^{\circ} \mathrm{C}$ ( $28 \%$ of the 133 mated females) $\left(F_{1,183}=4.28 ; P=0.039\right)$. Because of a marginally significant interaction of temperature and endosymbiont infection status on the model $\left(\mathrm{F}_{1,183}=3.61 ; P=0.057\right)$, a step-down analysis of the endosymbiont effect on sex ratio was performed for each thermal treatment separately. This revealed that the effect of endosymbionts on $\mathrm{M}$ brood production was only detectable at $20^{\circ} \mathrm{C}$ $\left(F_{1,133}=10.38 ; P<0.001\right)$, whereas the $M$ brood production was similar between mated $\mathrm{I}_{\mathrm{CW}}$ and $\mathrm{U}$ females at $25^{\circ} \mathrm{C}\left(\mathrm{F}_{1,50}=1.45 ; P\right.$ $=0.21$ ). Furthermore, our model did not detect an effect of constrained sex allocation on offspring number $\left(F_{1,183}=1.63 ; P=\right.$ 0.09).

Further analyses of the offspring sex ratios of individual females showed that mated unconstrained $\mathrm{I}_{\mathrm{CW}}$ females producing $\mathrm{F}$ broods had a lower percentage of male offspring (more femalebiased) than mated unconstrained $U$ females producing $\mathrm{F}$ broods at both 20 and $25^{\circ} \mathrm{C}$ (Table 1). However, the percentage of male offspring of mated constrained females producing $M$ broods did not differ between $\mathrm{I}_{\mathrm{CW}}$ or $\mathrm{U}$ in both temperature treatments. Beyond this, for both mated $\mathrm{I}_{\mathrm{CW}}$ and $\mathrm{U}$ females, temperature did not impact the sex ratio of $\mathrm{F}$ broods and $\mathrm{M}$ broods (Table 1 ).

\section{Effect of temperature on $\mathrm{Cl}$}

All incompatible pairs $\left(\mathrm{U} \times \mathrm{I}_{\mathrm{CW}}\right)$ at 20 and $25^{\circ} \mathrm{C}$ (experiment 3 ) resulted in male-only offspring, and, therefore the expression of $\mathrm{Cl}$ was complete and independent of temperature (Fig. 3a; Table 2). The total number of offspring produced was significantly lower for incompatible pairs than for compatible pairs at both temperatures (Table 2), indicating that the coinfection of Cardinium and Wolbachia in males resulted in the mortality of fertilized eggs of uninfected females (FM-Cl), as also observed in a previous study (Nguyen et al. 2017). However, the number of sons produced by $\mathrm{U} \times \mathrm{I}_{\mathrm{CW}}$ pairs at $25^{\circ} \mathrm{C}$ was nearly $40 \%$ higher than at $20^{\circ} \mathrm{C}\left(\mathrm{F}_{1,50}=\right.$ 11.94; $P<0.001$ ) (Fig. 3b; Table 2), suggesting a switch from $\mathrm{FM}-\mathrm{Cl}$

Table 1. Comparison of sex ratios (as \% males) in broods of unconstrained mated females (with $\mathrm{F}$ broods) and constrained mated females ( $\mathrm{M}$ broods) of pairs with different endosymbiont infections $\left(\mathrm{I}_{\mathrm{CW}} \times \mathrm{I}_{\mathrm{CW}} ; \mathrm{U} \times \mathrm{U}\right.$ ) at 20 and $25^{\circ} \mathrm{C}$ (data of all three crossing experiments are pooled).

\begin{tabular}{|c|c|c|c|c|}
\hline \multirow[t]{2}{*}{ Temperature } & \multirow[t]{2}{*}{ Offspring type } & \multicolumn{2}{|c|}{ Sex ratio median (1st-3rd quartile) } & \multirow{2}{*}{$\begin{array}{l}\text { Wilcoxon rank sum test (effect of } \\
\text { endosymbionts) }\end{array}$} \\
\hline & & $I_{c w} \times I_{c w}$ & $\mathbf{U} \times \mathbf{U}$ & \\
\hline \multirow[t]{2}{*}{$20^{\circ} \mathrm{C}$} & $\mathrm{F}$ broods & $0(0-3.03)$ & $2.44(0-4.35)$ & $W=792, P=\mathbf{0 . 0 2}$ \\
\hline & M broods & $100(100-100)$ & $100(100-100)$ & $W=127, P=0.512$ \\
\hline $25^{\circ} \mathrm{C}$ & M broods & $100(100-100)$ & $100(95.34-100)$ & $W=67.5, P=0.057$ \\
\hline $\begin{array}{l}\text { Wilcoxon rank sum test (effect of } \\
\text { temperature) }\end{array}$ & F broods & $\begin{array}{l}W=565.6 \\
P=0.09\end{array}$ & $W=172.5, P=0.103$ & \\
\hline
\end{tabular}

Sex ratio is presented as median, with 1 st and 3rd quartile values in parentheses. $P$ values $<0.05$ that are statistically significant are shown in bold. 

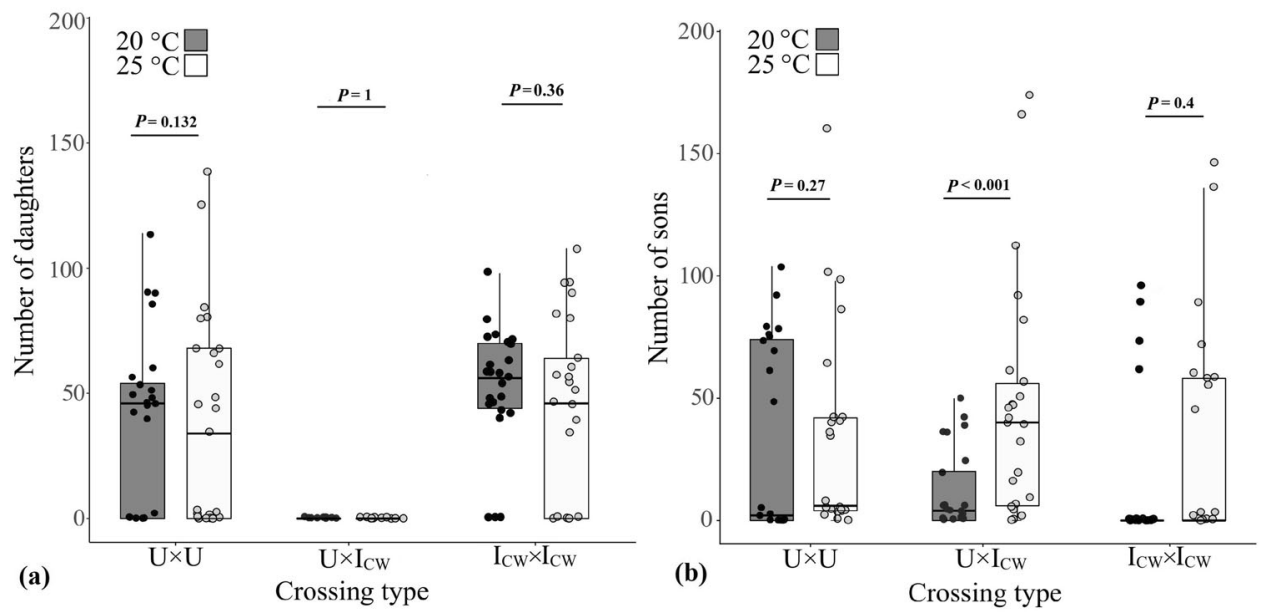

Fig. 3 Adult offspring number of crossing types at different temperatures. Numbers of (a) adult female and (b) male offspring produced by different crossing types when reared at 20 or $25^{\circ} \mathrm{C}$ (experiment 3). Box plots are represented with a jittered dot-plot overlay, with each dot representing the number of adult female or male offspring produced by individual pairs of compatible pairs of uninfected (U $\times U$ ) or infected $\left(\mathrm{I}_{\mathrm{CW}} \times \mathrm{I}_{\mathrm{CW}}\right)$ individuals as well as incompatible pairs $\left(\mathrm{U} \times \mathrm{I}_{\mathrm{CW}}\right)$ experiencing cytoplasmic incompatibility. Boxes include the median, the first and the third quartile range; whiskers represent the minimum and maximum range of the samples; outliers are shown as circles that did not fall within the bounds of whiskers.

to a partial $\mathrm{MD}-\mathrm{Cl}$ at the higher temperature. Furthermore, at $25^{\circ} \mathrm{C}$, the $\mathrm{U} \times \mathrm{I}_{\mathrm{CW}}$ pairs also produced more sons than the compatible $I_{\mathrm{CW}} \times \mathrm{I}_{\mathrm{CW}}$ pairs further suggesting the expression of MD-Cl (Table 2).

\section{Effect of temperature on endosymbiont density}

Overall, Wolbachia densities were substantially higher (between 8 and 92-fold) than Cardinium densities. Furthermore, there was a strong effect of sex on Wolbachia densities with higher normalised Cq values for $f b p A\left(F_{1,32}=6.05 ; P=0.021\right)$ and $\operatorname{cox} A\left(F_{1,32}=4.91\right.$; $P=0.036)$ in females than in males. However, no effect of sex was detectable on Cardinium densities, with the analysis performed on gyr $B$ Cq values $\left(F_{1,32}=3.08 ; P=0.09\right)$. Furthermore, temperature did not significantly affect densities of Wolbachia (fbpA: $\mathrm{F}_{3,32}=$ 1.69; $P=0.19$; coxA: $F_{3,32}=1.51 ; P=0.21$ ) or Cardinium (gyrB: $F_{3,32}=1.47 ; P=0.24$ ) (Fig. 4), and there was no interaction between sex and temperature for both endosymbionts densities (fbpA: $\mathrm{F}_{2,32}=0.39 ; P=0.68 ; \operatorname{cox} A: \mathrm{F}_{2,32}=0.13 ; P=0.87 ;$ gyrB: $\mathrm{F}_{2,32}$ $=0.37 ; P=0.69$ ).

\section{DISCUSSION}

We demonstrated that endosymbionts can moderate constrained sex allocation ( $M$ brood production) in a haplodiploid host species, and this occurred independently from any $\mathrm{Cl}$ effects on sex allocation, and in a temperature-dependent way. We found that the proportion of $P$. kellyanus females mated with compatible males experiencing constrained sex allocation was diminished by the presence of both Cardinium and Wolbachia at $20^{\circ} \mathrm{C}$, and this endosymbiont effect was temperature-sensitive as it disappeared with the increase of temperature to $25^{\circ} \mathrm{C}$. These findings may explain previous studies which demonstrated that the population sex ratios of $P$. kellyanus became less female-biased when reared at higher temperatures in the laboratory (Varikou et al. 2012), and were seasonally fluctuating in field environments (NavarroCampos et al. 2013).

Our finding of temperature-sensitive sex allocation is consistent with sex ratio patterns observed in several other haplodiploid taxa (Bondy and Hunter 2019). This has been recognized in some Hymenoptera species in which exposure to higher temperatures can cause increased maternal investment in male production (e.g., King 1987; Moiroux et al. 2014). Similar temperature-mediated sex ratio patterns were also found in whiteflies (Hemiptera), where this was suggested to be linked with a lower survival rate of females than males at higher temperatures (Cui et al. 2008). In a mealybug species (Hemiptera), higher male production observed at higher temperature (Nelson-Rees 1960) was suggested to be associated with factors regulating paternal genome elimination or change in endosymbiont densities (Ross et al. 2010a). However, the potential role of endosymbionts in temperature-sensitive sex allocation patterns remained mostly unexplored in haplodiploids.

\section{Temperature effect on constrained sex allocation}

Thermal stress, and in particular elevated temperature, can undermine the strength of endosymbiont-induced $\mathrm{Cl}$ in incompatible crosses (Hoffmann et al. 1986; Corbin et al. 2017). In some hosts, weaker Wolbachia-induced $\mathrm{Cl}$ was observed at higher temperatures and this was linked to the decline in endosymbiont density in male reproductive tissues (e.g., Breeuwer and Werren 1993; Ross et al. 2019). Nevertheless, a recent study of a Cardinium-infected parasitoid wasp species, Encarsia suzannae, showed that a temperature effect on $\mathrm{Cl}$ was not associated with its effect on endosymbiont density but with the duration of the pupal stage when testes development occurs (Doremus et al. 2019). Furthermore, high temperature can result in $\mathrm{Cl}$ becoming apparent in crosses that would otherwise be compatible. For example, Wolbachia-infected Aedes aegypti mosquito females which developed at high temperatures became partially incompatible with males reared at the same high temperature, probably because females lost their ability to rescue $\mathrm{Cl}$ due to a lower Wolbachia density, while males largely retained the capacity to induce $\mathrm{Cl}$ (Ross et al. 2019). In comparison, our study demonstrated for the incompatible crossing type $U \times I_{C W}$ stable levels of $\mathrm{Cl}$-induction across 20 and $25^{\circ} \mathrm{C}$ (except for a shift from $\mathrm{FM}-\mathrm{Cl}$ to a partial $\mathrm{MD}-\mathrm{Cl}$ at the higher temperature), whereas, for the compatible (rescuing) crossing type $\mathrm{I}_{\mathrm{CW}} \times \mathrm{I}_{\mathrm{CW}}$ it was found that the frequency of females suffering from constrained sex allocation (and therefore producing only males) increased at the higher temperature. This could suggest temperature-sensitive changes in the rescue (but not the induction) of $\mathrm{Cl}$. However, we found that Cardinium and Wolbachia densities in both males and females remained steady across the examined temperature regimes. Therefore, increased constrained sex allocation seen in compatible crosses at the higher temperature may not be due to an overall decline in endosymbiont density in females. Nevertheless, $\mathrm{Cl}$ may still arise in compatible crosses at higher temperatures due to a 
Table 2. Offspring number of Pezothrips kellyanus crosses (experiment 3) in response to the interactive effects of temperature and crossing type (endosymbiont infection).

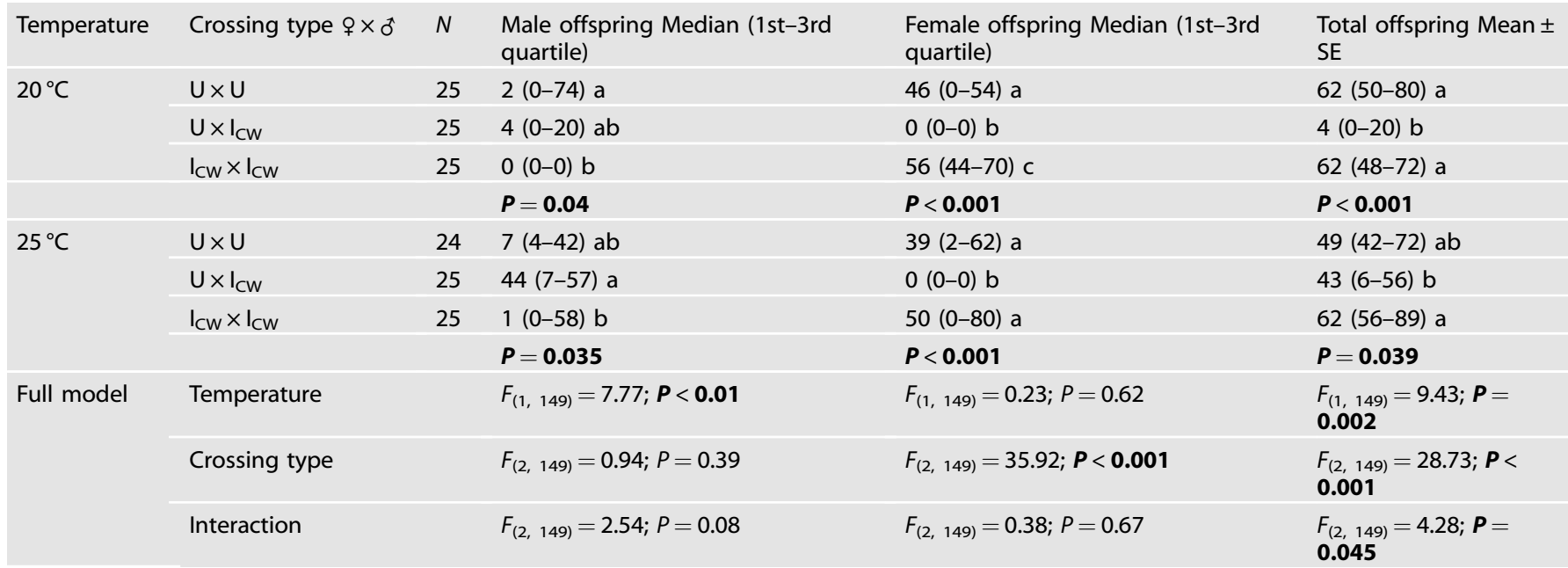

$N$ is the number of pairs. Male, female and total offspring number are presented as median ( 1 st and 3 rd quartile). $P$ values $<0.05$ that are statistically significant are shown in bold. Pairwise comparisons were conducted among crossing types within each temperature treatment. Medians that are significantly different are followed by different letters.

shift in endosymbiont localization patterns (Clark et al. 2003). If this was to apply then future experiments should test for any titre changes in reproductive tissues. However, we also note that there are examples of temperature-dependent Wolbachia titre changes that do not affect $\mathrm{Cl}$ outcomes in hosts. For example, in the parasitoid Leptopilina heterotoma a temperature change from 14 to $25^{\circ} \mathrm{C}$ did not influence the $\mathrm{Cl}$ strength, despite a change in Wolbachia density (Mouton et al. 2006).

For P. kellyanus it has previously been shown that, at $20^{\circ} \mathrm{C}$, the coinfection of Cardinium and Wolbachia causes $\mathrm{FM}-\mathrm{Cl}$, whereas Cardinium alone can induce moderate $\mathrm{MD}-\mathrm{Cl}$; therefore, it was concluded that Wolbachia overrides the MD-Cl of Cardinium (Nguyen et al. 2017). A dominance of FM-Cl over MD-Cl has also been shown for L. heterotoma coinfected with several Wolbachia strains with different $\mathrm{Cl}$ types (Mouton et al. 2005). In our $\mathrm{Cl}$ experiment, an increase from 20 to $25^{\circ} \mathrm{C}$ caused increased male production. This may suggest a partial shift from $\mathrm{FM}-\mathrm{Cl}$ to $\mathrm{MD}-\mathrm{Cl}$, possibly because the Wolbachia induced $\mathrm{FM}-\mathrm{Cl}$ function is more temperature-sensitive than the Cardinium MD-Cl function.

We further hypothesize that the increased male production at the higher temperature may be due to an increase in constrained sex allocation. We have previously found that constrained sex allocation in $P$. kellyanus is linked with lower fertilization rates (Katlav et al. 2021a). Therefore, increased constrained sex allocation may prevent the expression of $\mathrm{Cl}$ (which is only ever manifested in fertilized embryos of haplodiploid hosts). Future research should investigate whether the increased male production seen at higher temperatures is due to changes in $\mathrm{Cl}$ rescue and/or whether endosymbionts affect fertilization. Furthermore, and in the context of $\mathrm{Cl}$ in haplodiploids, perhaps the differences in $\mathrm{Cl}$ types ( $\mathrm{FM}-\mathrm{Cl}$ vs. MD-Cl) are a manifestation of endosymbiontdependent changes in constrained sex allocation in host species, and this needs further testing.

\section{Do endosymbionts moderate constrained sex allocation via metabolic provisioning?}

A role of metabolic provisioning of the host by endosymbionts has been demonstrated in several empirical studies (Newton and Rice 2020; Currin-Ross et al. 2021). For example, Wolbachia can increase female fecundity in Drosophila flies by influencing iron homeostasis (Brownlie et al. 2009). In filarial nematodes, Wolbachia provisions the host with heme and riboflavin (Foster et al. 2005). Likewise, in a spider species, synthesis of fat and free amino acids has been shown to be improved by a Wolbachia and Cardinium coinfection (Li et al. 2020), and in bedbugs, Wolbachia plays a nutritional role in vitamin B synthesis (Hosokawa et al. 2010). Similarly, in whiteflies, the endosymbionts Hamiltonella and Arsenophonus contribute to the biosynthesis of B vitamins that facilitate oogenesis and higher fertilization rate (Wang et al. 2020). Furthermore, a positive role of Wolbachia in the fertilization rate of haplodiploids has previously been reported for the spider mite $T$. urticae (Vala et al. 2003) and the parasitoid wasp Habrobracon hebetor (Bagheri et al. 2021), yet the underlying physiological mechanisms are unknown.

Recently, it has been demonstrated that egg size plays a role in the fertilization success of haplodiploids, e.g., in P. kellyanus (Katlav et al. 2021b) and T. urticae (Macke et al. 2011), with higher fertilization rates for larger eggs. It has also been revealed that constrained sex allocation in $P$. kellyanus is associated with maternal condition (but not paternal fitness or failure in sperm transfer), because constrained females are smaller and produce smaller eggs than unconstrained females (Katlav et al. 2021a). Possibly, the higher $\mathrm{F}$ brood production in $\mathrm{I}_{\mathrm{CW}} \times \mathrm{I}_{\mathrm{CW}}$ than $\mathrm{U} \times \mathrm{U}$ is associated with a potential role of Cardinium and/or Wolbachia in metabolic provisioning. Therefore, we further hypothesize that endosymbionts may interact with the host's egg size-mediated fertilization system, and this needs further investigation. Furthermore, a study on Lepidoptera has suggested that fertilization success increases with the number of micropyles on the egg (lossa et al. 2016). Whether the egg size-mediated fertilization in haplodiploids is linked with a variation in the number and/or size of micropyles, and whether endosymbionts play a role in this, also still remains to be explored.

\section{Constrained sex allocation as an adaptive or non-adaptive response to endosymbiont infection}

Several studies have shown that biased sex ratio patterns at the adult stage may be associated with sex-specific developmental mortality which consequently also results in a reduced adult offspring number (Werren and Charnov 1978; Nagelkerke and Hardy 1994). However, here we showed that endosymbiont effects on sex ratio patterns did not affect adult offspring numbers. Therefore, the increased proportion of $M$ broods in the infected population at higher temperature was not associated with a higher 


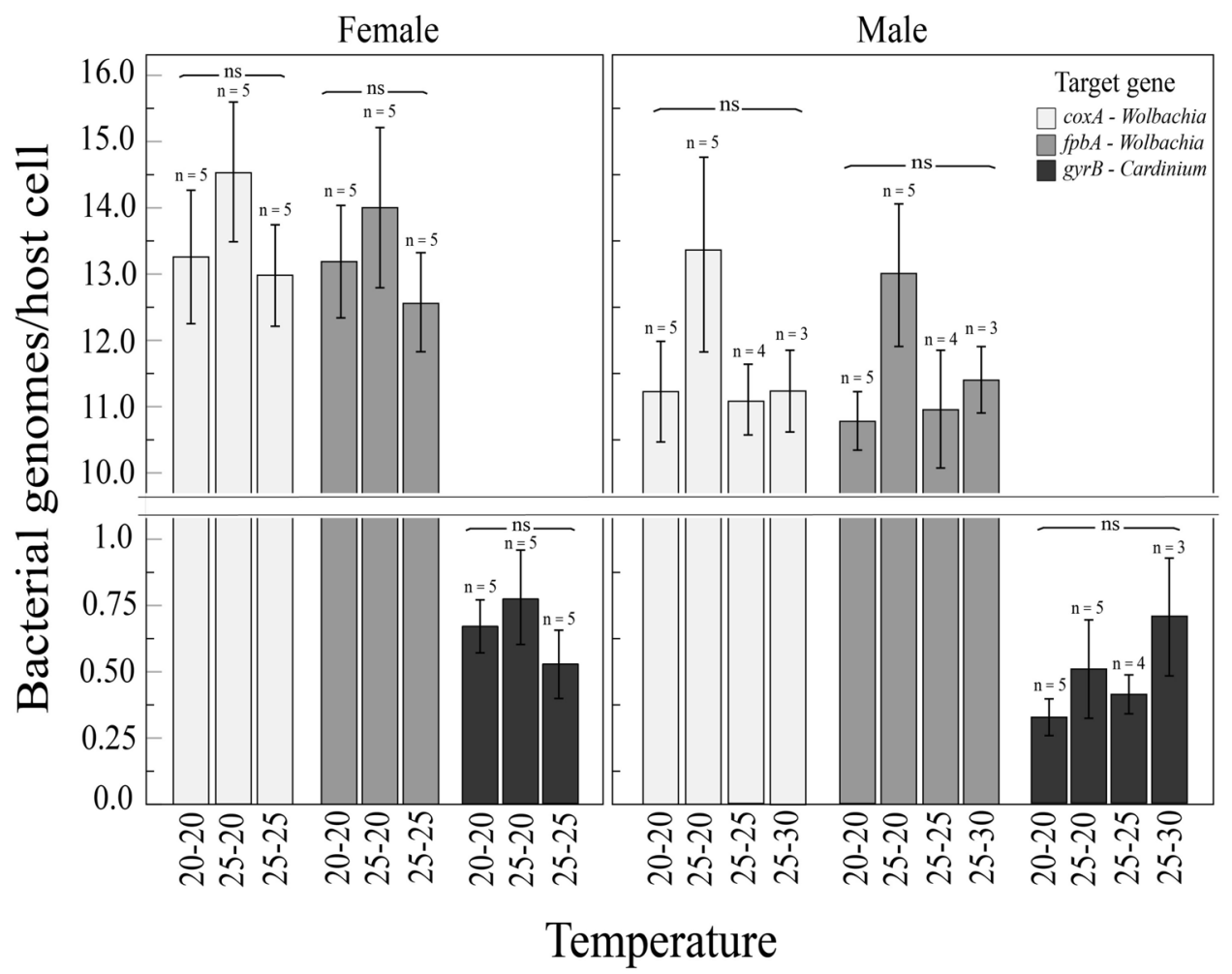

Fig. 4 Comparison of Cardinium and Wolbachia density in $\mathrm{I}_{\mathrm{cw}}$ females and males when reared at different temperatures across two successive generations (G1-G2). Mean $( \pm$ SE) quantification cycle values (Cq) and individual data points of the single copy genes coxA and fbpA (for Wolbachia density) and gyrB (for Cardinium density) were normalized $\left(2^{-\Delta C q}\right)$ to the host reference gene (EF1a). Error bars represent standard error and "ns" denotes non-significant difference of infections densities at $P<0.05$ across temperature treatments, shown separately for each target gene in adult females and males.

developmental mortality of female offspring, but probably a shift in the host's sex allocation (primary sex ratio). This temperaturedependent adjustment of sex allocation in response to endosymbiont infection is consistent with two alternative processes:

1. Non-adaptive response: under this scenario, constrained sex allocation is a consequence of physiological constraints preventing egg fertilization. In $P$. kellyanus, sex allocation of a female is associated with her condition. Some females fail to meet a required fitness threshold (body size) to facilitate fertilization success and, therefore, female production. Such fitness-dependant sex allocation has been revealed for a parasitic wasp species (Seidelmann et al. 2010). A growing number of studies have shown that elevated temperature can shorten developmental time by accelerating the larval metabolism (e.g., Murray et al. 2013; Zulkifli et al. 2018). This faster development can, consequently, result in smaller adults (Stearns 1992). Varikou et al. (2009) showed such a negative relationship between temperature and development time in $P$. kellaynus. Therefore, faster development of offspring at higher temperature could lead to smaller females which consequently fail to sufficiently provision eggs to ensure fertilization (Katlav et al. 2021a).

2. Adaptive response: under this scenario, constrained sex allocation may have evolved as an adaptive strategy of females in response to their energy budget that is affected by endosymbiont infection. Katlav et. al (2021b) found females developing from smaller eggs suffer a higher mortality rate than males. Therefore, this strategy may allow females to avoid fertilization of eggs that are not sufficiently provisioned, which would then lead to unsuccessful female development. Similar adaptive decisions have been observed in the oviposition behaviour of several parasitoid wasp species, where females can pause abdominal movements to ensure fertilization of the egg by a sperm cell (Martel and Boivin 2007; Moiroux et al. 2014).

Host-endosymbiont conflict over constrained sex allocation Maternally inherited endosymbionts may favour females to produce more daughters because males are a dead end for endosymbionts (Egas et al. 2002). However, for some females it can be beneficial to increase male production, especially when the population sex ratio is female-biased. Such host-endosymbiont conflicts over sex allocation have received substantial attention (Hurst 1992; Werren and Beukeboom 1998; Ross et al. 2010b). In P. kellyanus, there may be an evolutionary arms race between the host and the endosymbionts over sex allocation. Endosymbionts may select for increased F brood production (Werren 2011); conversely, the host may select for increased $M$ brood production to avoid a highly female-biased population sex ratio (Godfray 1990) caused by endosymbionts, resulting in constrained sex allocation patterns. We demonstrated that constrained sex allocation is more intense in females of an uninfected population from which endosymbionts had been removed. Constrained sex allocation may have evolved as a female strategy to avoid cost of $\mathrm{Cl}$ (especially $\mathrm{FM}-\mathrm{Cl}$ ) by avoiding fertilisation of their eggs with incompatible sperm. A similar postcopulatory strategy for minimizing risk of $\mathrm{Cl}$ has been shown for polyandry of Drosophila fruit flies in which multiple-mated females can potentially exploit the higher competitive ability of sperm of uninfected over infected males (Champion de De Crespigny et al. 2006; Price and Wedell 2008). However, the higher probability of constrained sex allocation in females without endosymbionts may result in a lower chance for an uninfected population to grow. This is consistent with the observation that uninfected $P$. kellyanus individuals are scarce in field populations (Nguyen et al. 2016), 
indicating that the endosymbionts have been able to spread to fixation not only due to $\mathrm{Cl}$, but perhaps also due to a reduced constrained sex allocation caused by one or both endosymbionts.

\section{CONCLUSIONS}

In summary, our study demonstrated that the role of common endosymbionts such as Wolbachia and Cardinium in host reproduction is beyond the induction of commonly recognized reproductive manipulations (like $\mathrm{Cl}$ manifested between infected and uninfected individuals) and may occur through changes in sex allocation in compatible crosses that can lead to increased female production. In haplodiploid populations, production of uninfected males as an outcome of $\mathrm{Cl}$ can limit the invasion success of $\mathrm{Cl}$, as uninfected females can maintain their fitness by mating with these uninfected males (Vavre et al. 2000). We propose that the observed effect of endosymbionts on sex allocation may constitute a strategy to compensate for the lower efficiency of $\mathrm{Cl}$ to drive endosymbiont invasion of haplodiploid host populations. On the other hand, the constrained sex allocation might be an outcome of the conflicts between the different optimal sex ratios aspired to by host and endosymbionts, with the host preferring more moderate population sex ratios than the female-biased sex ratios caused by endosymbionts. Given that Cardinium and Wolbachia may have different evolutionary trajectories and molecular mechanisms to affect hosts (Penz et al. 2012), future studies are yet to explore the net effect of each endosymbiont on constrained sex allocation in P. kellyanus separately. Finally, the temperature-dependent endosymbiont effect on sex ratio in P. kellyanus may provide insights into the evolution of temperaturedependent sex allocation mechanisms in many other arthropods.

\section{DATA AVAILABILITY}

The data used in this manuscript are available on figshare repository: https://doi.org/ 10.6084/m9.figshare.16456023.

\section{REFERENCES}

Bagheri Z, Talebi AA, Asgari S, Mehrabadi M (2021) Wolbachia promotes successful sex with siblings in the parasitoid Habrobracon hebetor. Pest Manag Sci 78:362-368

Bordenstein SR, Werren JH (2000) Do Wolbachia influence fecundity in Nasonia vitripennis? Heredity 84:54-62

Bordenstein SR, Uy JJ, Werren JH (2003) Host genotype determines cytoplasmic incompatibility type in the haplodiploid genus Nasonia. Genetics 164:223-233

Breeuwer JA, Werren JH (1993) Cytoplasmic incompatibility and bacterial density in Nasonia vitripennis. Genetics 135:565-574

Bressac C, Rousset F (1993) The reproductive incompatibility system in Drosophila simulans: DAPI-staining analysis of the Wolbachia symbionts in sperm cysts. J Invertebr Pathol 61:226-230

Brownlie JC, Cass BN, Riegler M, Witsenburg JJ, Iturbe-Ormaetxe I, McGraw EA, O'Neill SL (2009) Evidence for metabolic provisioning by a common invertebrate endosymbiont, Wolbachia pipientis, during periods of nutritional stress. PLoS Pathog 5:e1000368

Buchner P (1965) Endosymbiosis of animals with plant microorganisms. John Wiley and Sons, New York, NY

Clark ME, Veneti Z, Bourtzis K, Karr TL (2003) Wolbachia distribution and cytoplasmic incompatibility during sperm development: the cyst as the basic cellular unit of Cl expression. Mech Dev 120:185-198

Corbin C, Heyworth ER, Ferrari J, Hurst GD (2017) Heritable symbionts in a world of varying temperature. Heredity $118: 10-20$

Crespi BJ (1992) Eusociality in Australian gall thrips. Nature 359:724-726

Crespi BJ (1993) Sex ratio selection in Thysanoptera. In: Wrensch DL, Ebert M eds. Evolution and Diversity of Sex Ratio in Insects and Mites. Chapman and Hall, New York, NY, p 214-234

Cui X, Wan F, Xie M, Liu T (2008) Effects of heat shock on survival and reproduction of two whitefly species, Trialeurodes vaporariorum and Bemisia tabaci biotype B. J Insect Sci 8:24

Currin-Ross D, Husdell L, Pierens GK, Mok NE, O'Neill SL, Schirra HJ, Brownlie JC (2021) The metabolic response to infection with Wolbachia implicates the insulin/ insulin-like-growth factor and hypoxia signaling pathways in Drosophila melanogaster. Front Ecol Evol 9:158

De Crespigny FC, Pitt TD, Wedell N (2006) Increased male mating rate in Drosophila is associated with Wolbachia infection. J Evol Biol 19:1964-1972

Doremus MR, Kelly SE, Hunter MS (2019) Exposure to opposing temperature extremes causes comparable effects on Cardinium density but contrasting effects on Cardinium-induced cytoplasmic incompatibility. PLoS Pathog 15:e1008022

Doremus MR, Stouthamer CM, Kelly SE, Schmitz-Esser S, Hunter MS (2020) Cardinium localization during its parasitoid wasp host's development provides insights into cytoplasmic incompatibility. Front Microbiol 11:606399

Douglas AE (2015) Multiorganismal insects: diversity and function of resident microorganisms. Annu Rev Entomol 60:17-34

Egas M, Vala F, Breeuwer JAJ (2002) On the evolution of cytoplasmic incompatibility in haplodiploid species. Evolution 56:1101-1109

Evans JD, Shearman DCA, Oldroyd BP (2004) Molecular basis of sex determination in haplodiploids. Trends Ecol Evol 19:1-3

Foster J, Ganatra M, Kamal I, Ware J, Makarova K, Ivanova N et al. (2005) The Wolbachia genome of Brugia malayi: endosymbiont evolution within a human pathogenic nematode. PLoS Biol 3:e121

Godfray HCJ (1990) The causes and consequences of constrained sex allocation in haplodiploid animals. J Evol Biol 3:3-17

Gunnarsson B, Goodacre SL, Hewitt GM (2009) Sex ratio, mating behaviour and Wolbachia infections in a sheetweb spider. Biol J Linn Soc 98:181-186

Himler AG, Adachi-Hagimori T, Bergen JE, Kozuch A, Kelly SE, Tabashnik BE et al. (2011) Rapid spread of a bacterial symbiont in an invasive whitefly is driven by fitness benefits and female bias. Science 332:254-256

Hoffmann AA, Turelli M, Simmons GM (1986) Unidirectional incompatibility between populations of Drosophila simulans. Evolution 40:692-701

Hosokawa T, Koga R, Kikuchi Y, Meng XY, Fukatsu T (2010) Wolbachia as a bacteriocyte-associated nutritional mutualist. Proc Natl Acad Sci USA 107:769-774

Hurst LD (1992) Intragenomic conflict as an evolutionary force. Proc R Soc B: Biol Sci 248:135-140

Hurst GD, Johnson AP, Schulenburg JHGV, Fuyama Y (2000) Male-killing Wolbachia in Drosophila: a temperature-sensitive trait with a threshold bacterial density. Genetics 156:699-709

Hurst GD, Frost CL (2015) Reproductive parasitism: maternally inherited symbionts in a biparental world. Cold Spring Harb Perspect Biol 7:a017699

lossa G, Gage MJ, Eady PE (2016) Micropyle number is associated with elevated female promiscuity in Lepidoptera. Biol Lett 12:20160782

Kageyama D, Narita S, Watanabe M (2012) Insect sex determination manipulated by their endosymbionts: incidences, mechanisms and implications. Insects 3:161-199

Katlav A, Cook JM, Riegler M (2021b) Egg size-mediated sex allocation and matingregulated reproductive investment in a haplodiploid thrips species. Funct Ecol 35:485-498

Katlav A, Nguyen DT, Cook JM, Riegler M (2021a) Constrained sex allocation after mating in a haplodiploid thrips species depends on maternal condition. Evolution 75:1525-1536

Keller L, Liautard C, Reuter M, Brown WD, Sundström L, Chapuisat M (2001) Sex ratio and Wolbachia infection in the ant Formica exsecta. Heredity 87:227-233

King BH (1987) Offspring sex ratios in parasitoid wasps. Q Rev Biol 62:367-396

Li C, He M, Yun Y, Peng Y (2020) Co-infection with Wolbachia and Cardinium may promote the synthesis of fat and free amino acids in a small spider, Hylyphantes graminicola. J Invertebr Pathol 169:107307

Macke E, Magalhaes S, Khan HDT, Luciano A, Frantz A, Facon B, Olivieri I (2011) Sex allocation in haplodiploids is mediated by egg size: Evidence in the spider mite Tetranychus urticae Koch. Proc R Soc B: Biol Sci 278:1054-1063

Martel V, Boivin G (2007) Unequal distribution of local mating opportunities in an egg parasitoid. Ecol Entomol 32:393-398

Moiroux J, Brodeur J, Boivin G (2014) Sex ratio variations with temperature in an egg parasitoid: behavioural adjustment and physiological constraint. Anim Behav 91:61-66

Mouton L, Henri H, Bouletreau M, Vavre F (2005) Multiple infections and diversity of cytoplasmic incompatibility in a haplodiploid species. Heredity 94:187-192

Mouton L, Henri H, Bouletreau M, Vavre F (2006) Effect of temperature on Wolbachia density and impact on cytoplasmic incompatibility. Parasitology 132:49-56

Murray TJ, Tissue DT, Ellsworth DS, Riegler M (2013) Interactive effects of preindustrial, current and elevated atmospheric $\left[\mathrm{CO}_{2}\right]$ and temperature on an insect herbivore of Eucalyptus. Oecologia 171:1025-1035

Nagelkerke CJ, Hardy IC (1994) The influence of developmental mortality on optimal sex allocation under local mate competition. Behav Ecol 5:401-411

Navarro-Campos C, Pekas A, Aguilar A, Garcia-Marí F (2013) Factors influencing citrus fruit scarring caused by Pezothrips kellyanus. J Pest Sci 86:459-467 
Nelson-Rees WA (1960) A study of sex predetermination in the mealy bug Planococcus citri (Risso). J Exp Zool 144:111-137

Newton IL, Rice DW (2020) The Jekyll and Hyde symbiont: could Wolbachia be a nutritional mutualist? J Bacteriol 202:e00589-19

Nguyen DT, Morrow JL, Spooner-Hart RN, Riegler M (2017) Independent cytoplasmic incompatibility induced by Cardinium and Wolbachia maintains endosymbiont coinfections in haplodiploid thrips populations. Evolution 71:995-1008

Nguyen DT, Spooner-Hart RN, Riegler M (2015) Polyploidy versus endosymbionts in obligately thelytokous thrips. BMC Evol Biol 15:1-12

Nguyen DT, Spooner-Hart RN, Riegler M (2016) Loss of Wolbachia but not Cardinium in the invasive range of the Australian thrips species, Pezothrips kellyanus. Biol Invasions 18:197-214

Oliver KM, Degnan PH, Burke GR, Moran NA (2010) Facultative symbionts in aphids and the horizontal transfer of ecologically important traits. Annu Rev Entomol 55:247-266

Penz T, Schmitz-Esser S, Kelly SE, Cass BN, Müller A, Woyke T et al. (2012) Comparative genomics suggests an independent origin of cytoplasmic incompatibility in Cardinium hertigii. PLoS Genet 8:e1003012

Price TA, Wedell N (2008) Selfish genetic elements and sexual selection: their impact on male fertility. Genetica 134:99-111

Ros VID, Breeuwer JAJ (2009) The effects of, and interactions between, Cardinium and Wolbachia in the doubly infected spider mite Bryobia sarothamni. Heredity 102:413-422

Ross L, Langenhof MB, Pen I, Beukeboom LW, West SA, Shuker DM (2010a) Sex allocation in a species with paternal genome elimination: the roles of crowding and female age in the mealybug Planococcus citri. Evol Ecol Res 12:89-104

Ross L, Pen I, Shuker DM (2010b) Genomic conflict in scale insects: the causes and consequences of bizarre genetic systems. Biol Rev 85:807-828

Ross PA, Ritchie SA, Axford JK, Hoffmann AA (2019) Loss of cytoplasmic incompatibility in Wolbachia-infected Aedes aegypti under field conditions. PLoS Negl Trop Dis 13:e0007357

Schmittgen TD, Livak KJ (2008) Analyzing real-time PCR data by the comparative CT method. Nat Protoc 3:1101-1108

Seidelmann K, Ulbrich K, Mielenz N (2010) Conditional sex allocation in the red mason bee, Osmia rufa. Behav Ecol Sociobiol 64:337-347

Shan HW, Luan JB, Liu YQ, Douglas AE, Liu SS (2019) The inherited bacterial symbiont Hamiltonella influences the sex ratio of an insect host. Proc R Soc B: Biol Sci 286:20191677

Snook RR, Cleland SY, Wolfner MF, Karr TL (2000) Offsetting effects of Wolbachia infection and heat shock on sperm production in Drosophila simulans: analyses of fecundity, fertility and accessory gland proteins. Genetics 155:167-178

Stearns SC (1992) The evolution of life histories. Oxford University Press.

Stouthamer R, Hurst GD, Breeuwer JA (2002) Sex ratio distorters and their detection. Sex ratios. Concepts and research methods. In: Hardy ICW ed. Sex Ratios Concepts and Research Methods. Cambridge University Press, Cambridge, p 195-215

Turelli M (1994) Evolution of incompatibility-inducing microbes and their hosts. Evolution 48:1500-1513

Vala F, Breeuwer JAJ, Sabelis MW (2003) Sorting out the effects of Wolbachia, genotype and inbreeding on life-history traits of a spider mite. Exp Appl Acarol 29:253-264

Varikou K, Tsitsipis I, Alexandrakis V, Hoddle M (2009) Effect of temperature on the development and longevity of Pezothrips kellyanus (Thysanoptera: Thripidae). Ann Entomol Soc Am 102:835-841

Varikou K, Birouraki A, Tsitsipis I, Sergentani CHR (2012) Effect of temperature on the fecundity of Pezothrips kellyanus (Thysanoptera: Thripidae). Ann Entomol Soc Am 105:60-65

Vavre F, Fleury F, Varaldi J, Fouillet P, Bouleatreau M (2000) Evidence for female mortality in Wolbachia-mediated cytoplasmic incompatibility in haplodiploid insects: epidemiologic and evolutionary consequences. Evolution 54:191-200

Vavre F, Fouillet P, Leury F (2003) Between-and within-host species selection on cytoplasmic incompatibility-inducing Wolbachia in haplodiploids. Evolution 57:421-427

Wang YB, Ren FR, Yao YL, Sun X, Walling LL, Li NN et al. (2020) Intracellular symbionts drive sex ratio in the whitefly by facilitating fertilization and provisioning of $B$ vitamins. ISME J 14:2923-2935

Weinert LA, Araujo-Jnr EV, Ahmed MZ, Welch JJ (2015) The incidence of bacterial endosymbionts in terrestrial arthropods. Proc R Soc B: Biol Sci 282:20150249

Werren JH (2011) Selfish genetic elements, genetic conflict, and evolutionary innovation. Proc Natl Acad Sci USA 108:10863-10870

Werren JH, Charnov EL (1978) Facultative sex ratios and population dynamics. Nature 272:349-350

Werren JH, Baldo L, Clark ME (2008) Wolbachia: master manipulators of invertebrate biology. Nat Rev Microbiol 6:741-751
Werren JH, Beukeboom LW (1998) Sex determination, sex ratios, and genetic conflict. Annu Rev Ecol Evol Syst 29:233-261

White JA, Kelly SE, Perlman SJ, Hunter MS (2009) Cytoplasmic incompatibility in the parasitic wasp Encarsia inaron: disentangling the roles of Cardinium and Wolbachia symbionts. Heredity 102:483-489

Wobbrock JO, Findlater L, Gergle D, Higgins JJ (2011) The aligned rank transform for nonparametric factorial analyses using only ANOVA procedures. In Proceedings of the SIGCHI Conference on Human Factors in Computing Systems, Vancouver, BC, Canada (7-12May 2011). ACM, New York, NY, p 143-146

Zug R, Hammerstein P (2015) Bad guys turned nice? A critical assessment of Wolbachia mutualisms in arthropod hosts. Biol Rev 90:89-111

Zulkifli AN, Zakeri HA, Azmi WA (2018) Food consumption, developmental time, and protein profile of the digestive system of the red palm weevil, Rhynchophorus ferrugineus (Coleptera: Dryophthoridae) larvae reared on three different diets. J Insect Sci 18:1-7

\section{ACKNOWLEDGEMENTS}

The authors thank two anonymous reviewers for constructive feedback, Greg Baker and Peter Crisp (SARDI) for supply of the thrips colony, the Hawkesbury Earth Care Centre and Ross Hitchcock for the supply of organic lemons.

\section{AUTHOR CONTRIBUTIONS}

DTN, RNSH and MR conceptualised the study and developed the experimental design. DTN and JLM collected the data, AK, DTN, JLM and MR analysed and interpreted the data. AK, DTN and MR wrote the manuscript with input from all other authors. All authors agreed to the submitted manuscript.

\section{FUNDING}

This project was supported by Western Sydney University Postgraduate Research Awards to DTN and AK, and an Australia and Pacific Science Foundation research grant (APSF16/5) to MR. Open Access funding was enabled and organized by CAUL and its Member Institutions.

\section{COMPETING INTERESTS}

The authors declare no competing interests.

\section{ADDITIONAL INFORMATION}

Supplementary information The online version contains supplementary material available at https://doi.org/10.1038/s41437-022-00505-5.

Correspondence and requests for materials should be addressed to Markus Riegler.

Reprints and permission information is available at http://www.nature.com/ reprints

Publisher's note Springer Nature remains neutral with regard to jurisdictional claims in published maps and institutional affiliations.

\footnotetext{
(c) (i)

Open Access This article is licensed under a Creative Commons Attribution 4.0 International License, which permits use, sharing, adaptation, distribution and reproduction in any medium or format, as long as you give appropriate credit to the original author(s) and the source, provide a link to the Creative Commons license, and indicate if changes were made. The images or other third party material in this article are included in the article's Creative Commons license, unless indicated otherwise in a credit line to the material. If material is not included in the article's Creative Commons license and your intended use is not permitted by statutory regulation or exceeds the permitted use, you will need to obtain permission directly from the copyright holder. To view a copy of this license, visit http://creativecommons. org/licenses/by/4.0/.
}

(c) The Author(s) 2022 